\title{
Investigation of Flow Phenomena in a Transonic Fan Rotor Using Laser Anemometry
}

Anthony J. Strazisar

Lewis Research Center

Cleveland, Ohio

Prepared for the

Twenty-ninth Annual International Gas Turbine Conference sponsored by the American Society of Mechanical Engineers Amsterdam, The Netherlands, June 3-7, 1984 


\title{
INVESTIGATION OF FLOW PHENOMENA IN A TRANSONIC FAN \\ ROTOR USING LASER ANEMOMETRY
}

\author{
Anthony J. Strazisar \\ National Aeronautics and Space Administration \\ Lewis Research Center \\ Cleveland, Ohio 44135
}

\section{ABSTRACT}

Several flow phenomena including flow field periodicity, rotor shock oscillation, and rotor shock system geometry have been investigated in a transonic low aspect ratio fan rotor using laser anemometry. Flow periodicity is found to increase with increasing rotor pressure rise, and to correlate with blade geometry variations. Analys is of time-accurate laser anemometer data indicates that the rotor shock oscillates about its mean location with an amplitude of 3 to 4 percent of rotor chord. The shock surface is nearly two-dimensional for levels of rotor pressure rise at and above the peak efficiency level but becomes more complex for lower levels of pressure rise. Spanwise shock lean generates radial flows due to streamline deflection in the hub-to-shroud stream surface.

\section{NOMENCLATURE}

A shock motion amplitude

$\mathrm{CH}$ denotes choke flow compressor operating point

DF denotes design flow compressor operating point

$f \quad$ shock motion frequency

M mass flow

$M_{S} \quad$ shock motion mach number

MN Mach number component normal to the shock surface

MR denotes midrange compressor operating point

MREL local relative Mach number component in the 20 plane

NS denotes near stall compressor operating point

P total pressure

p static pressure

PE denotes peak efficiency compressor operating point

PR rotor total pressure ratio

S1 blade-to-blade stream surface 
S2 hub-to-shroud midgap stream surface

$R \quad$ radius, radial direction

$t \quad$ time

us shock motion velocity

$x_{S}$ shock position

$Z$ axial direction

ZS2 streamwise distance along the midgap $S 2$ stream surface

as shock lean angle in the midgap 52 stream surface

aSL streamline slope in the midgap S2 stream surface (positive toward the tip)

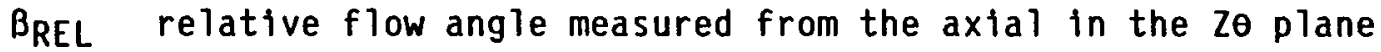

BS shock sweep angle in the S1 stream surface

ws steady state shock pressure loss coefficient

$\omega_{u}$. unsteady shock pressure loss coefficient

\section{SUBSCRIPTS}

ss denotes steady state

$u$ denotes unsteady

1 conditions upstream of a shock

2 conditions downstream of a shock

20 denotes quantities calculated by neglecting streamline slope and shock lean

30 denotes quantities calculated by including streamline slope and shock lean

\section{INTRODUCTION}

In recent years several investigators have presented detailed internal laser anemometer flow field measurements in transonic axial-flow compressors ( 1 to 4 ). The results obtained have traditionally been used by computational fluid mechanic researchers as a data base for validation of numerical flow field solution techniques ( 5 to 9 ). Internal flow field measurements will continue to be used for this purpose as computational methods evolve toward viscous-inviscid interaction schemes and eventually toward fully viscous solution schemes.

Such measurements can also be used to improve our understanding of several flow phenomena within transonic blade rows in order to improve empirical models 
which are stiil used in the blade design process. Two recent investigators ( 9 and 10$)$ have attempted to refine the classic Miller-Lewis-Hartman loss model based on normal shocks (11) to include effects of shock obliquity in the blade-to-blade and spanwise direction. Another recent investigation has provided evidence that the strength of the rotor passage shock may vary considerably from passage-to-passage and may be time unsteady as well (12). Both of these phenomena can impact overall performance in that they can both cause higher loss than one would predict for a steady flow which is uniform in al1 passages. It may therefore be possible to improve blade row performance by understanding the origin of such effects and modifying the blade design to minimize them. Other areas of current research interest which require internal flow fleld data are the development of secondary flow and wake mixing models and the effect of blade row interactions on individual blade row performance.

The NASA Lewis Research Center has undertaken a program aimed at obtaining detalled measurments within transonic blade rows which satisfy the need for internal flow fleld data generated by research interests in the above areas. The first phase of this program involves mapping of the flow in a transonic low aspect ratio fan rotor in sufficient detail to enable accurate determination of the three-dimensional rotor shock structure and the response of the flow field to varying backpressure conditions. Flow phenomena such as shock unsteadiness, flow periodicity, and shock-driven radial flows have also been investigated. Results obtained from these measurements are the subject of this report. Later phases of the current program include mapping of the flow field through controlled diffusion stators operating behind the fan rotor, and a study of the impact of blade row interaction on the intra-rotor flow field and the wake mixing rate.

\section{LASËR ANEMOMETER SYSTEM}

"The laser anemometer (LA) system used in the present investigation is a single channel fringe anemometer which has been previously described in detail $(4,13,14)$. Optical access to the flow field is provided by a $3 \mathrm{~mm}$ thick glass window which conforms to the outer flowpath contour in both the circumferential and streamwise directions. The clearance between the window and the rotor tip is $0.5 \mathrm{~mm}$ at design speed. The laser beams enter the test compressor in a nominally radial direction. However, the beams can be deflected off-radial to minimize regions near the blade root which are blocked from optical access by spanwise blade twist, and to enable the measurement of radial velocity components. Liquid seed particles which are nominally 1-1.4 microns in diameter are injected into the flow through a $6 \mathrm{~mm}$ diameter tube located $35 \mathrm{~cm}$ upstream of the rotor.

The circumferential location of each velocity measurement relative to the rotor is determined by tagging the measurement with a pulse from a variable frequency clock which is phase locked to the rotor rotational speed. The clock frequency is set to give 50 pulses per blade passing. All measurements which occur within an interval between adjacent clock pulses are assigned to a "rotor shaft position", which is defined as the center of the interval. The blade geometry is used to calculate the rotor shaft position which corresponds to the blade suction surface at any axial, radial point within the rotor. LA measurements are obtained within a data window which starts on the suction surface of a given blade and contains 50 shaft positions blade-to-blade across 17 of the 22 rotor blades. The time required for the passing of the last five blades is used to reset the clock frequency to track rotor speed drift and to perform on-line data reduction. A typical run consists of obtaining 60000 
measurements within the data window, which yields about 70 measurements at each of the 850 shaft positions if the data are evenly distributed.

Data may be gathered in either a data average mode or a data capture mode. In the data average mode, only the sum of the velocities, the sum of the velocities squared, and the number of measurements are recorded at each shaft position. Although the velocity mean and standard deviation are calculated from these three quantities, all information on the distribution of the velocities which occurred at each shaft position are lost. Since only three words of storage are required for each shaft position, a data window which is 850 shaft positions wide requires only 2550 words of storage independent of the number of measurements requested in a run. In the data capture mode each individual velocity measurement which occurs at a shaft position is recorded. This mode allows analysis of the distribution of the velocity meaurements which occurred at each shaft position and is useful for the analysis of flow steadiness as will be shown later. However, this mode of operation requires two words of storage for each velocity measurement. A typical run in which 60000 measurements are requested therefore requires 120000 words of storage. The data average mode was therefore used for most of the measurements reported here.

Laser anemometer measurement locations are shown in Fig. 1, which is a meridional view of the test rotor. Conventional pressure and temperature traverse data are obtained at stations 1 and 2 shown in the figure. LA measurements are made along conical surfaces which pass through radii corresponding to 10 percent mass flow fractions at the rotor trailing edge. These conical surfaces are generated by straight line interpolation between design streamline radil which are known at stations 1 and 2 and the blade edges. Measurement locations are distributed axially at 20 percent chord intervals from -100 percent to -20 percent chord, at -10 percent chord, at 2.5 percent chord intervals from -5 percent to 10 percent chord, at 10 percent chord intervals from 10 percent to 100 percent chord, and at aerodynamic survey stations 1 and 2 . Surveys are also taken at 4 locations evenly spaced between the rotor trailing edge and the stator leading edge plane and at the stator leading edge plane.

\section{TEST COMPRESSOR}

The test rotor for the present study is a low aspect ratio fan. The rotor design pressure ratio is 1.63 at a massflow of $33.25 \mathrm{~kg} / \mathrm{sec}$. The tip relative Mach number is 1.38 at the design tip speed of $429 \mathrm{~m} / \mathrm{sec}$. The rotor has 22 blades, an aspect ratio of 1.56 (based on average span/root axial chord), an inlet tip diameter of $51.3 \mathrm{~cm}$, and an inlet hub/tip radius ratio of 0.375 . The rotor tip clearance at design speed is $0.5 \mathrm{~mm}$. The rotor does not have a part-span shroud which is typically required to prevent flutter in fan stages of higher aspect ratio. Details of the rotor aerodynamic design are given in (15).

The results reported here were obtained from a rotor-only configuration with the stator removed. This configuration eliminates circumferential variations in the flow field induced by stationary blade rows and thus allows comparison of the measurements with numerical predictions based on circumferentially uniform upstream and downstream conditions.

The rotor design speed operating line is shown in Fig. 2 for both the rotor-only and fuli-stage (rotor+stator) configurations. Mass flow is measured across a calibrated orifice located far upstream of the compressor. The rotor pressure rise is calculated from mass-averaged total pressure surveys obtained at aerodynamic survey stations 1 and 2 shown in Fig. 1. 
Laser anemometer ineasurements were obtained on all nine stream surfaces at the near stall (NS) and peak efficiency (PE) operating points. At the midrange (MR) operating condition, measurements were made on the $10,20,30,40,60$, and 80 percent span stream surfaces. Additional LA surveys were obtained on selected stream surfaces at the choke (CH) and design flow (DF) operating points.

Note that the rotor stall point occurs at a higher mass flow in the rotor-only configuration than in the full stage configuration. One explanation is that the presence of the stators may be suppressing the development of rotating stall within the rotor. A second possibility is that, in the motor-only case, rotor stall may be triggered by a flow separation in the test rig diffuser which is located between the rotor and throttle valve. with the stators removed, the flow entering the diffuser still contains most of the rotor exit swirl, which generates a relatively high absolute Mach number. In either case, the near stall flow field measurements obtained in the rotor-only case may not be representative of the flow field just prior to rotor blade stall. However, the measurements obtained at the NS operating point do provide a set of data which is consistent with that obtained at other operating points along the rotor-only design speed line.

\section{FLOW PERIODICITY}

In reporting on LA measurements obtained in a $550 \mathrm{~m} / \mathrm{sec}$ tip speed fan rotor with a part-span shroud, Harvey et al. (12) have shown significant non-periodicity in the flow field at the design speed peak efficiency operating condition. Some rotor blade passages displayed nearly shock-free flow while other passages displayed the expected normal shock characteristics. Harvey also observed that the flow was much more periodic at the design speed near stall point and at part speed operating conditions than at the design speed peak efficiency condition. The pattern of non-periodic flow was frozen to the rotor, 1 .e. the same flow always occurred in the same blade passage, which suggests that blade geometry variations were the cause of the non-periodicity. However, the blades were not avallable for inspection when the non-periodicity was discovered. In reporting on measurements obtained in a $426 \mathrm{~m} / \mathrm{sec}$ tip speed unshrouded compressor rotor the present author 4 has shown that flow field variations from passage-to-passage were on the order of 5 percent or less except for local variations around the blade leading edges.

The above results prompted an investigation of both the running blade geometry and the flow field periodicity in the present fan rotor: The fan geometry at design speed was measured by focussing the LA probe volume on the blade tip. The LA system clock frequency was increased from the usual 50 cycles (shaft positions) per blade passage to 1000 shaft positions per passage, yielding a circumferential resolution of $0.008 \mathrm{~mm}$ between shaft positions. The position of each rotor blade was measured at 14 axial locations for 50 rotor revolutions. The results indicate a high degree of geometric uniformity within the rotor. The spacing between blades was uniform to within 2 percent and the blades moved by less than 0.1 of blade spacing relative to one another during the 50 measured revolutions. The blade tip LA measurements indicated an untwist of $1.96 \pm 0.04$ degrees compared to a finite element analysis prediction of 2.02 degrees.

Blade-to-blade relative Mach number distributions across the 17 measured blades are shown in Fig. 3. In order to decrease the statistical uncertainty of these measurements at each shaft position, the total number of measurements acquired across the 17-blade data window was increased from 60000 to 450000 , 
which would yield approximately 500 measurements at each shaft postion if the data were uniformly distributed. Data obtained at the peak efficiency point at 30 percent span, 30 percent chord is shown in Fig. 3(a). Data obtained at the near stall point at 30 percent span, 20 percent chord is shown in Fig. 3(b). The peak efficiency Mach number distributions suggest a two-shock system in the rotor with a front shock inlet Mach number of 1.35 to 1.4 and a rear shock inlet Mach number of 1.25 to 1.3. Note that the two-shock system appears in all rotor passages.

The data indicate that the flow field in individual passages can be spatially averaged together to provide an accurate representation of the flow field in an "average" blade passage. The data also supports the observation of Harvey et.al. in that the flow is much more periodic near stall than at peak efficiency. The degree of periodicity within the present rotor is closer to that observed in the unshrouded NASA compressor rotor than to that observed by Harvey et al. in the shrouded fan rotor. It would therefore appear that rotor geometry variations caused by part-span shrouds might be the cause of flow field non-periodicity. However, the higher tip speed of the shrouded fan rotor might also contribute to the observed periodicity levels.

One explanation for the increased non-periodicity observed at peak efficiency is as follows. Choke flow operating points are often characterized by an oblique shock system in the rotor tip region. As the back pressure is raised and the mass flow decreases, the shock structure transitions to a normal shock structure. Because the flow field is at a transition point between these two shock structures near the peak efficlency operating condition, it may be most sensitive to blade geometry variations and small flow perturbations at this flow point.

An interesting feature of $\mathrm{Fig} .3(\mathrm{a})$ is the flow field in passage 12 which is clearly different than all other passages at peak efficiency and which lies outside the envelope of all other blade passage Mach number distributions at midgap for the near stall condition. Blade number 12 has a strain guage mounted at 50 percent chord, 30 percent span on the blade suction surface, which is also the point at which the rotor passage shock hits the blade surface. Analysis of flow periodicity 20 percent of chord downstream of the trailing edge at peak efficiency indicates that the suction side of blade wake 12 also lies outside the envelope of all other blade wakes. These results demonstrate that surface mounted instrumentation located in transonic regions of the flow fleld can have a significant impact on individual blade performance.

\section{UNSTEADY SHOCK MOTION}

Shocks have been observed to oscillate about their mean location in schlieren photos and movies taken in wind tunnels and diffusers. It is therefore reasonable to expect that the shocks in transonic compressor rotors may also display motion about a mean position. Such motion can lead to an increase in net shock loss, since the increase in loss when the shock moves upstream (thus increasing the shock inlet Mach number) is greater than the loss decrease when the shock moves downstream (thus decreasing the shock inlet Mach number).

In order to investigate shock motion in the test rotor. LA data was acquired in the data capture mode described above. The results of one such run are shown in Figs. 4 and 5 . Figure 4 is a plot of the average blade-to-blade distribution of the axial velocity component measured at the near stall operating condition at 10 percent span, 20 percent chord. Figure 5 shows the histograms of the distribution of the individual measurements which 
occured in all blade passages at shaft positions a to $f$ shown in Fig. 4 . The ordinate of each figure is the number of measurements, $N$, which occurred in velocity "bins" which are $3 \mathrm{~m} / \mathrm{sec}$ in width, normalized by the number of measurements in the highest bin, NMAX. Since each histogram contains data from a 1117 blade passages at a given shaft position, it is possible that the width of each histogram is due to passage-to-passage flow variations as opposed to time-unsteadiness of the flow. However, inspection of histograms at a given shaft position in a single passage indicates that the averaged histograms shown here are not broadened due to flow non-periodicity.

On the upstream side of the shock (points $a, b)$ the most probable velocity is the pre-shock level of $198 \mathrm{~m} / \mathrm{sec}$. As one proceeds across the shock to positions $c$ and $d$ the occurence of the pre-and post-shock levels of $198 \mathrm{~m} / \mathrm{sec}$ and $140 \mathrm{~m} / \mathrm{sec}$ is almost equally probable. On the downstream side of the shock the post-shock level of $140 \mathrm{~m} / \mathrm{sec}$ is the most probable. The data suggests that the amplitude of the shock motion is on the order of 2 to 3 shaft positions on either side of the mean shock location shown in Fig. 4 . This corresponds to a distance of about $3 \mathrm{~mm}$ ( 3.5 percent chord) in a direction normal to the shock. Similar amplitudes have been observed at other spanwise locations for near stall as well as peak efficiency operating conditions. In addition, analysis of peak efficiency rotor wake data 50 percent chord downstream of the blade at 10 percent span indicates that the rotor wake oscillates by about 3 to 4 shaft positions about its mean location. This wake oscillation may be driven by the shock oscillation. If this is the case, it may be possible to infer the shock oscillation frequency by measuring the wake oscillation frequency using a high response total pressure transducer.

Although only the shock motion amplitude is known we can estimate the net increase in shock pressure loss for a given frequency by assuming a harmonic shock motion of frequency $F$ and amplitude $A$ in a direction normal to the shock surface. These assumptions yield

$$
\begin{gathered}
x_{S}=A \cdot \sin (2 \pi \cdot F t) \\
M_{S}=u_{S} / a_{\text {sound }}=\left(2 \pi \cdot F A / a_{\text {sound }}\right) \cdot \cos (2 \pi \cdot F t) \\
M N(t)=(M N)_{s S}+M_{S}
\end{gathered}
$$

where $x_{S}, u_{S}$, and $M_{S}$ are the position, speed and Mach number of the moving shock and $M N(t)$ and $M N_{S S}$ are the time varying and steady state Mach number components normal to the shock surface. Note that since the shock speed, $u_{s}$, is controlled by the product of the shock motion amplitude and frequency, shock motions of small amplitude and high frequency are equivalent to those of large amplitude and low frequency. A shock pressure loss coefficient can be defined as

$$
\omega_{s}=\left(1-P_{2} / P_{1}\right) /\left(1-p_{1} / P_{1}\right) \text {, }
$$

where $P_{2} / P_{1}$ is the total pressure ratio across a normal shock with an approach Mach number of $M N(t)$ and $p_{1} / p_{1}$ is the static-to-total pressure ratio associated with the fan inlet relative Mach number, MREL. Shock loss coefficients calculated for various values of $M_{S}$ for the shock shown in Fig. 4 are summarized in Table I. The unsteady loss, $\omega_{u}$, was calculated from a time average of $\mathrm{Eq}$. (4). The measured value of $\mathrm{MREL}=1.343$ was used to evaluate $p_{1} / P_{1}$. The total pressure ratio $P_{2} / P_{1}$ was evaluated at the shock normal Mach number given by $\mathrm{Eq}$. (3) using measured values of $\mathrm{MN}_{\mathrm{SS}}=$ 1.171 and $A=3 \mathrm{~mm}$. The results indicate that for the shock motion amplitude 
measured in this case, a shock frequency of $1 \mathrm{kH}$ can result in an 11 percent increase in net snuck pressure loss compared to a stationary shock. The existence of shock motion frequencies on this order does not seem to be unrealistic when viewed from the rotor time frame. Since the rotational speed of this rotor is on the order of 250 revs/second, a shock oscillating $1 \mathrm{kH}$ would go through about 4 cycles of motion per rotor revolution. Measurements of shock motion amplitude and frequency in rotors with different aerodynamic design features are clearly needed before we can determine to what extent the shock motion amplitudes measured here and the frequencies assumed here are characteristic of all transonic blade rows.

\section{PROCEDURE FOR DETERMINING SHOCK SURFACES}

The following sections deal with the response of the rotor shock system to varying backpressure levels and with the three-dimensionality of the shock surface. One flow field representation often used in such discussions is a blade-to-blade contour plot of relative Mach number. While such plots provide information throughout the blade-to-blade flow field, they do not provide an accurate indication of the rotor shock location when, as is often the case, the Mach number varies along the face of the shock. In such cases there is no single Mach number contour line which runs parallel to the shock. The following discussion therefore makes use of shock fronts determined from plots of the relative Mach number MREL in the blade-to-blade direction at constant chord such as Fig. 6 , and from plots of MREL in the streamwise direction at constant pitch relative to the suction surface, such as Fig. 7 .

Although the seed particle velocity does not accurately follow the gas velocity in the high deceleration region immediately downstream of the shock, the point at which the Mach number first begins to decrease is considered to be an accurate and consistent indicator of the shock location. The uncertainty in the shock location determined by this procedure is on the order of 2 shaft positions (4 percent of rotor pitch) in the circumferential direction and 1 percent of rotor axial chord in the axial direction. Both Figs. 6 and 7 indicate the existence of two shocks in the blade passage. The second shock, which occurs only for backpressures at or below the peak efficiency level, rarely shows up as clearly in blade-to-blade plots as it does in Fig. 6. Streamwise plots of MREL were found to provide a much more sensitive indication of the second shock location. In order to improve the spatial resolution of the streamwise plots, LA surveys were taken every 2.5 percent chord from the blade leading edge to 80 percent chord on the 10 percent to 40 percent span stream surfaces at the peak efficiency operating condition.

\section{SHOCK STRUCTURE AS A FUNCTION OF ROTOR PRESSURE RISE}

The response of the rotor shock system to varying backpressure levels is shown on the 10 percent and 30 percent span stream surfaces in Fig. 8 using the operating condition labels shown in Fig. 2 . In some cases the shock is not drawn all the way to the blade suction surface because the location of the shock-blade intersection point could not be determined from the data. This is due in part to the fact that data is missing at some axial survey locations and in part to the fact that the shock sometimes hits the blade between survey station locations. The bow wave angle, $\beta_{5}$, measured from the axial direction decreases while the passage shock angle increases with increasing pressure rise across the rotor. This flattening of the shock is consistent with an increase in the shock strength. The standoff distance between the 
shock and the blade leading edge decreases as the backpressure is raised from the choke flow level to the peak efficiency level. Further increases in backpressure then result in an increase in the standoff distance. For backpressure levels at and below peak efficiency a system of two oblique shocks exists. As the backpressure rises the second shock becomes less oblique as shown at 30 percent span and then disappears before the midrange condition is reached. At 10 percent span near stall the shock structure near the blade surface appears to be the front foot of a lambda shock. Mach number contour plots of the data in this region show a lambda-shaped grouping of Mach number contours, but a rear shock foot cannot be discerned from the data using the procedure described above for determining a shock surface location.

\section{THREE DIMENSIONAL ROTOR SHOCK STRUCTURE}

The three-dimensionality of the rotor shock structure is displayed at the peak efficiency, midrange, and near stall operating conditions in figs. 9((a) to $(c))$ respectively. The shaded blade section is the 10 percent span blade section. The intersection of each measurement stream surface between 20 percent and 60 percent span with the suction surface of the left blade and the pressure surface of the right blade is also shown to help locate the shock with respect to the blade surface. It should be noted that the apparent lean of the shock in the spanwise direction is a strong function of the procedure used to construct a figure of this type. The blade section at each span is shown at the blade spacing appropriate for that span, 1.e., BLADE SPACING $=2 \pi$ RSLOCAL/NB, where RSLOCAL is the local stream surface radius and NB is the number of rotor blades. In addition the blade sections are aligned circumferentially according to their position relative to a radial line which passes through the 10 percent span stream surface at midgap at the blade leading edge. This line, referred to as the view axis in each figure, was chosen because it passes approximately through the center of the shock surface. Viewing along this line therefore gives the least distorted two-dimensional representation of the shock surface.

The near stall shock surface shown in Fig. $9(a)$ is nearly planar with little curvature in the blade-to-blade (or S1) surface. The shock sweep angle in the $S 1$ surface is nearly constant along the face of the shock and is independent of span as well. At the midrange flow condition the sweep angle begins to vary along the face of the shock at a given span. The bow shock sweep angle also begins to vary with span. However, the bow and passage shock surfaces are each nearly planar in themselves. At the peak efficiency condition the bow and front passage shock are no longer planar. The bow shock angle varies significantly with span. The passage shock angle with respect to the axial direction decreases rapidly above 30 percent span and the shock surface becomes nearly vertical above 20 percent span. The rear passage shock sweep angle and axial location above 30 percent span are quite different than those below 30 percent span. These characteristics lead to a highly complex shock structure outboard of 30 percent span.

Certain features of the results shown above agree quite well with the empirical shock models proposed by Prince (9) and Wennerstrom (10). A normal shock appears to be a quite accurate model for the shock surface except for the outboard regions of the blade at relatively low backpressure operating conditions. Under those conditions Prince has proposed an axial front passage shock which turns near the blade suction surface so as to approach the blade normal to the surface. This model agrees quite well with the peak efficiency data. The extent to which these results are generic remains to be determined 
by obtaining L.A data on rotors which have different design characteristics than the present rotor.

The intersection of the passage shock and the blade leading edge with the midgap meridional (or S2) surface is shown in $\mathrm{Fig} .10$. The abscissa, $\mathrm{Z}_{\mathrm{S} 2}$, is the distance measured in the streamwise direction in the midgap $S 2$ stream surface. Note that the front shock lean angle in the 52 surface, $\alpha_{s}$, is nearly independent of both span and rotor operating condition with the exception of the tip region at peak efficiency. The shock sweep angle in the S1 surface, $\beta_{S}$, the lean angle in the midgap S2 surface, $\alpha_{S}$, and the design streamiline slope in the $S 2$ surface, aSL, were combined with the inlet relative Mach number and flow angle measured in he $2 \theta$ plane (MREL, $\beta_{R E L}$ ) to calculate the true Mach number components normal to the shock surface at midgap. The isentropic shock relations were then used to calculate the true Mach number change across the shock and the shock loss coefficient defined in Eq. (4). The relative Mach number and flow angle and the shock sweep angle were also used to calculate the Mach number change and loss across the shock which one would predict by neglecting streamline slope and shock lean. The results are summarized in Table II for the peak efficiency operating condition. Subscript 2D refers to quantities calculated by neglecting shock lean and streamline slope while subscript 30 refers to quantities calculated by including these effects.

As one would expect, including shock lean in the calculations results in higher post-shock Mach numbers and significantly lower shock loss than calculated by neglecting the lean. Mach number changes measured across the shock by the LA are generally in better agreement with the 30 calculations than with the 2D calculations. Consider for example the front passage shock at 30 percent span, peak efficiency. From Table II we see that the shock is nearly normal to the relative flow in the sl surface $\left(\beta_{S}+\beta_{R E L}=93.9^{\circ}\right)$, which leads to a 20-calculated post shock Mach number of 0.76 . However, when the shock lean and streamline slope are included in the calculation, the post-shock Mach number is 1.06 . The Mach number measured by the LA system behind this shock is approximately 1.2 as seen in Fig. 7. There are many others examples of this type in the data in which supersonic Mach numbers measured downstream of shocks which are normal in the Sl surface can be explained by shock lean in the spanwise direction.

The results shown in Table II also indicate that the streamline slope changes across the shock due to streamline deflection toward the tip in the 52 surface. A limited number of radial velocity component measurements were acquired with the LA to investigate the existence of such shock-driven radial flows. These measurements require that the laser beams be deflected off-radial by rotation about an axis parallel to the compressor axis of rotation. When this is attempted inside the blade row the rotor blades block the incoming laser beams and prevent data acqusition across much of the blade pitch. Blade-to-blade radial velocity component data was therefore acquired just upstream of they rotor at -5 percent chord from 10 percent to 40 percent span at the near stall operating condition. Post-shock streamline slopes on the order of 4 to $16^{\circ}$ were measured just behind the shock. After the flow re-expanded further downstream of the shock, the measured streamline slopes were on the order of 0 to $-4^{\circ}$, which agree with the design levels of streamline slope.

\section{CONCLUSION}

Flowfield survey data acquired with a laser anemometer has been used to investigate several features of the flow field in a transomic low aspect ratio 
fan rotor. The data also provides a more extensive set of flow field data on a single rotor than avallable in the past for use in validation of numerical flow field predictions.

Investigation of the flow fleld periodicity indicates that the flow becomes more periodic as the level of rotor pressure rise increases. In addition, surface-mounted instrumentation gives rise to significant flow field changes.

Laser anemometer data acquired in a time-accurate mode of operation indicates that the rotor passage shock oscillates about its mean location with an amplitude on the order of 3 to 4 percent of rotor chord, while the rotor wake oscillates about its mean location with an amplitude of about 4 to 6 percent of blade pitch. Calculation of the increase in shock loss due to shock oscillation requires that the oscillation frequency be known. Although this frequency cannot be determined from the LA data, estimates of the loss increase based on the assumption of harmonic shock motion at moderate frequencies indicates that shock motion may indeed contribute to part of the total shock loss in transonic blade rows.

The rotor passage shock is a nearly two-dimensional surface with spanwise lean for levels of rotor pressure rise which are at or above the peak efficiency level. Under these conditions, several features of the shock structure are in agreement with recently proposed shock models. However, at pressure rise levels below peak efficiency, a two-shock system develops in the rotor with complex surface curvatures in the outboard region of the front shock and along the entire spanwise extent of the rear shock. The extent to which these results are generic remains to be determined by obtaining LA data on rotors which have different design characteristics than the present rotor.

Spanwise lean of the shock surface generates radial flows due to streamline deflection across the shock in the hub-to-shroud stream surface. These radial flows have been measured in the present investigation at a point upstream of the rotor, but cannot be measured inside the rotor with the present optical configuration. A new configuration capable of acquiring radial flow data within the rotor blade will be used in future investigations.

\section{REFERENCES}

1) Wisler, D. C., "Shock Wave and Flow Velocity Measurements in a High-Speed Fan Rotor Using the Laser Velocimeter," Journal of Engineering for Power. Vol. 99, No. 2, Apr. 1977, pp. 181-188.

2) Dunker, R. J., Strinning, P. E., and Weyer, H. B., "Experimental Study of the Flow Field Within a Transonic Axial Compressor Rotor by Laser Velocimetry and Comparison With Through-Flow Calculations," Journal of Engineering for Power, Vo1. 100, No. 2, Apr. 1978, pp. 279-286.

3) Weyer, H. B. and Dunker, R., "Dual Beam Laser Anemometer Study of the Flow Field in a Transonic Compressor," Secondary Flows in Turbomachines, AGARD CP-214, Mar. 1977.

4) Strazisar, A. J. and Powe11, J. A., "Laser Anemometer Measurements in a Transonic Axial Flow Compressor Rotor," Journal of Engineering for Power. Vol. 103, No. 2, Apr. 1981, pp. 430-437. 
5) McDonald, P. W., et a1. "A Comparson between Measured and Computed Flow Fields in a Transonic Compressor Rotor," ASME Paper No. 80-GT-7, 1980.

6) Chima, R. V. and Strazisar, A. J., "Comparison of Two- and ThreeDimensional Flow Computations with Laser Anemometer Measurements in a Transonic Compressor Rotor," Journal of Engineering for Power, Vol. 105, No. 3, July 1983, pp. 596-605.

7) Sarathy, K. P., "Computation of Three-Dimensional Flow Fields Through Rotating Blade Rows and Comparison with Experiment," Journal of Engineering for Power," Vol. 104, No. 2, Apr. 1982, pp. 394-402.

8) Singh, U.K., "A Computation and Comparison with Measurements of Transonic Flow in an Axial Compressor Stage with Shock and Boundary Layer Interaction," Journal of Engineering for Power, Vo1. 104, No. 2, Apr. 1982, pp. 510-515.

9) Prince, D. C. Jr., "Three-Dimensional Shock Structure for Transonic/Supersonic Compressor Rotors," Journal of Aircraft, Vo 1. 17, No. 1, Jan. 1980, pp. 28-37.

10) Wennerstrom, A. J. and Puterbaugh, S. L., "A Three-Dimensional Model for the Prediction of Shock Losses in Compressor Blade Rows," ASME Paper No. 83-GT-216, 1983.

11) Miller, G. R., Lewis, G. W., Jr., and Hartmann, M. J., "Shock Losses in Transonic Compressor Blade Rows," Journal of Engineering for Power. Vol. 83, No. 3, July 1961, pp.235-242.

12) Harvey, W. B., et al. "Rotor Redesign for a Highly Loaded $1800 \mathrm{ft} / \mathrm{sec}$ Tip Speed Fan, III. Laser Doppler Velocimeter Report," NASA CR-167954, PWA-5523-122, Apr. 1982.

13) Powe11, J. A., Strazisar, A. J., and Seasholtz, R. G., "Efficient Laser Anemometer for Intra-Rotor Flow Mapping in Turbomachinery," Journal of Engineering for Power, Vol. 103, No. 2, Apr. 1981, pp. 424-429.

14) Powe11, J. A., Strazisar, A. J., and Seasholtz, R. G., "High-Speed Laser Anemometer System for Intrarotor Flow Mapping in Turbomachinery," NASA TP-1663, Feb. 1982 .

15) Urasek, D. C., Gorre11, W. T., and Cunnan, W. S., "Performance of Two-Stage Fan Having Low-Aspect-Ratio, First-Stage Rotor Blading," NASA TP-1493, AVRADCOM TR-78-49 Aug. 1979. 
TABLE I. - SHOCK LOSS AS A FUNCTION OF SHOCK MOTION

FOR 10 PERCENT SPAN, 20 PERCENT CHORD, NEAR STALL.

Shock motion amplitude $=3 \mathrm{~mm}$

Inlet relative Mach number $=1.343$

Steady state shock normal Mach number $=1.171$

Steady state shock loss $\omega_{s}=.00717$

\begin{tabular}{|c|c|c|c|}
\hline Frequency (Hz) & $M_{S}$ & $\omega_{u}$ & $\omega_{u} / \omega_{S}$ \\
\hline 0 & 0 & .00717 & 1.000 \\
500 & .028 & .00735 & 1.025 \\
1000 & .056 & .00789 & 1.110 \\
2500 & .141 & .01153 & 1.608 \\
5000 & .281 & .02191 & 3.056 \\
\hline
\end{tabular}

TABLE II. - SHOCK JUMP CONDITIONS CALCULATED AT ROTOR MIDGAP FOR THE PEAK

EFFICIENCY OPERATING CONDITION.

\begin{tabular}{|c|c|c|c|c|c|c|c|c|c|c|}
\hline \multicolumn{6}{|c|}{ Pre-shock } & \multicolumn{5}{|c|}{ Post-shock } \\
\hline Span & ${ }^{\alpha} s$ & $\beta_{S}$ & MREL & ${ }^{B}{ }_{R E L}$ & ${ }^{\alpha} \mathrm{SL}$ & $(M R E L)_{20}$ & $\left(\right.$ MREL) ${ }_{30}$ & ${ }^{\alpha} \mathrm{SL}$ & $\left(W_{5}\right)_{2 D}$ & $\left(W_{s}\right)_{3 D}$ \\
\hline \multicolumn{11}{|c|}{ Front shock } \\
\hline $\begin{array}{l}10 \\
20 \\
30 \\
40 \\
50 \\
60\end{array}$ & $\begin{array}{l}81.0 \\
81.0 \\
60.0 \\
63.0 \\
63.0 \\
63.0\end{array}$ & $\begin{array}{r}3.5 \\
4.5 \\
35.0 \\
22.0 \\
26.0 \\
23.0\end{array}$ & $\begin{array}{l}1.35 \\
1.31 \\
1.36 \\
1.32 \\
1.22 \\
1.16\end{array}$ & $\begin{array}{l}61.9 \\
60.9 \\
58.9 \\
56.7 \\
56.0 \\
53.2\end{array}$ & $\begin{array}{r}-4.4 \\
-3.2 \\
-2.1 \\
-1.0 \\
0.3 \\
1.6\end{array}$ & $\begin{array}{r}1.00 \\
1.01 \\
.76 \\
.83 \\
.85 \\
.94\end{array}$ & $\begin{array}{l}1.01 \\
1.02 \\
1.06 \\
1.07 \\
1.10 \\
\star\end{array}$ & $\begin{array}{l}2.7 \\
2.6 \\
8.7 \\
7.1 \\
3.3 \\
\star\end{array}$ & $\begin{array}{l}.015 \\
.010 \\
.048 \\
.030 \\
.013 \\
.003\end{array}$ & $\begin{array}{c}.015 \\
.009 \\
.016 \\
.006 \\
.0007\end{array}$ \\
\hline \multicolumn{11}{|c|}{ Rear shock } \\
\hline $\begin{array}{l}10 \\
20 \\
30 \\
40 \\
50\end{array}$ & $\begin{array}{l}86.5 \\
86.5 \\
90.0 \\
90.0 \\
79.0\end{array}$ & $\begin{array}{c}13.0 \\
9.5 \\
32.0 \\
56.0 \\
55.0\end{array}$ & $\begin{array}{l}1.29 \\
1.26 \\
1.23 \\
1.20 \\
1.12\end{array}$ & $\begin{array}{l}58.7 \\
57.9 \\
54.5 \\
49.7 \\
50.0\end{array}$ & $\begin{array}{r}-4.6 \\
-3.5 \\
-2.2 \\
-1.0 \\
0.3\end{array}$ & $\begin{array}{l}.92 \\
.99 \\
.83 \\
.93 \\
.97\end{array}$ & $\begin{array}{r}.92 \\
.99 \\
.83 \\
.93 \\
1.02\end{array}$ & $\begin{array}{r}-.5 \\
0.1 \\
-1.0 \\
-.3 \\
1.3\end{array}$ & $\begin{array}{l}.015 \\
.007 \\
.017 \\
.006 \\
.001\end{array}$ & $\begin{array}{l}.016 \\
.007 \\
.017 \\
.006 \\
.0004\end{array}$ \\
\hline
\end{tabular}

*30 calculations result in subsonic inlet Mach number component normal to the shock surface 



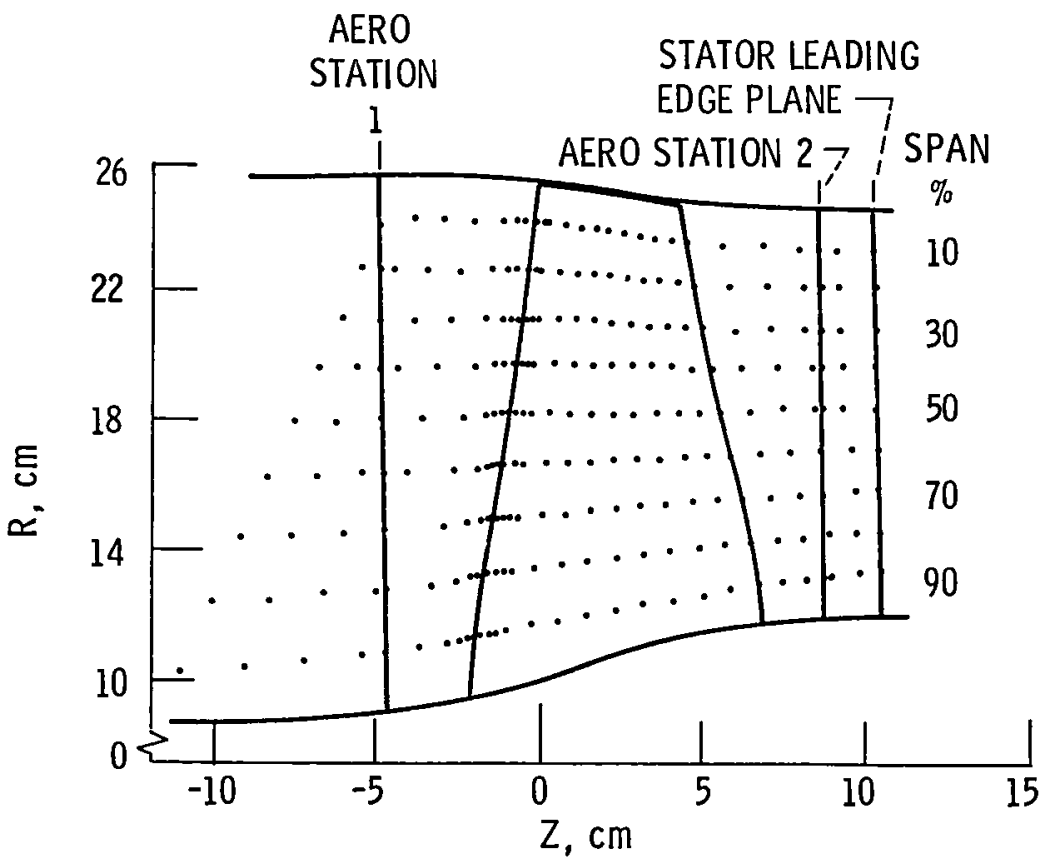

Figure 1. - Meridional view of the test fan showing laser anemometer and aerodynamic survey locations.

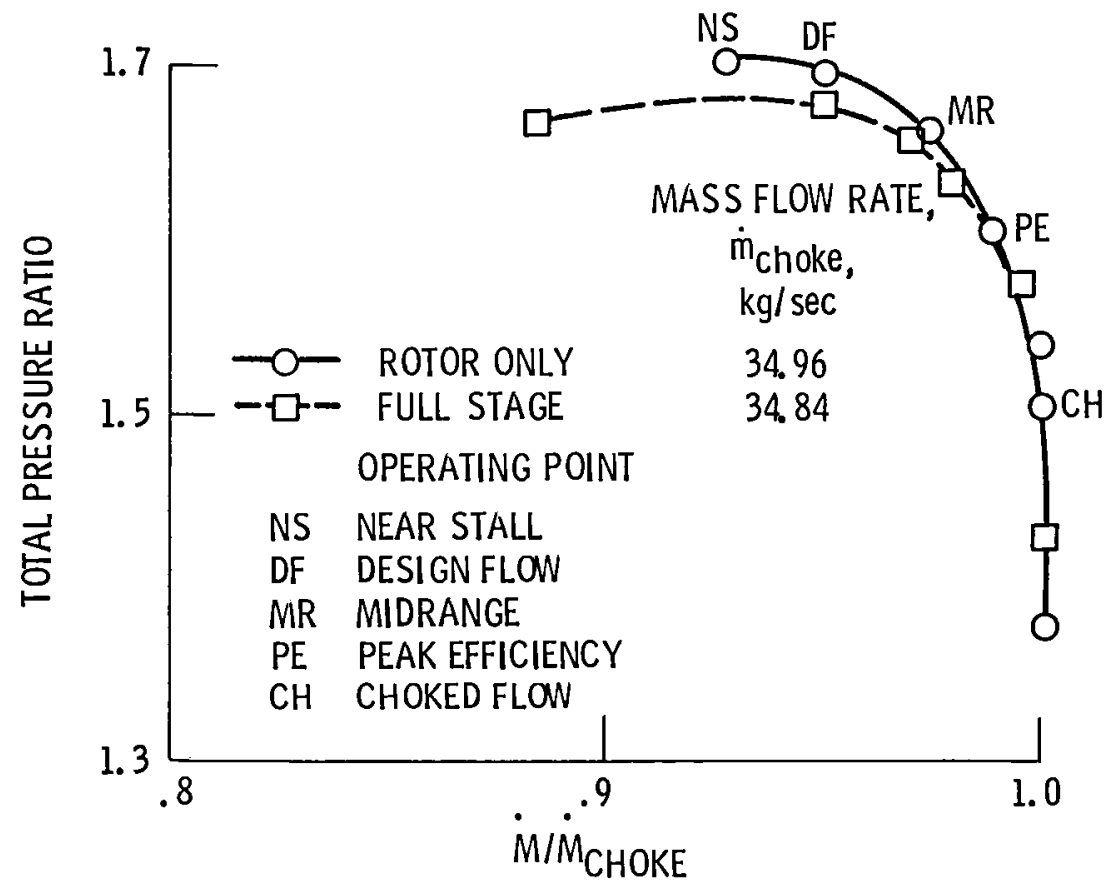

Figure 2. - Rotor design speed operating line. 


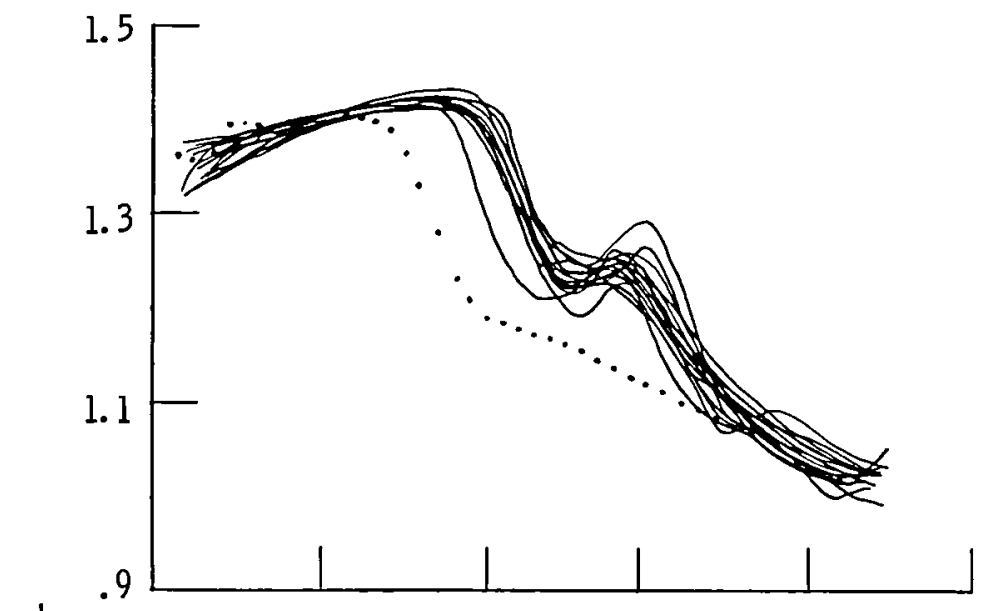

岁 $\quad$ (a) $30 \%$ span, $30 \%$ chord at peak efficiency.

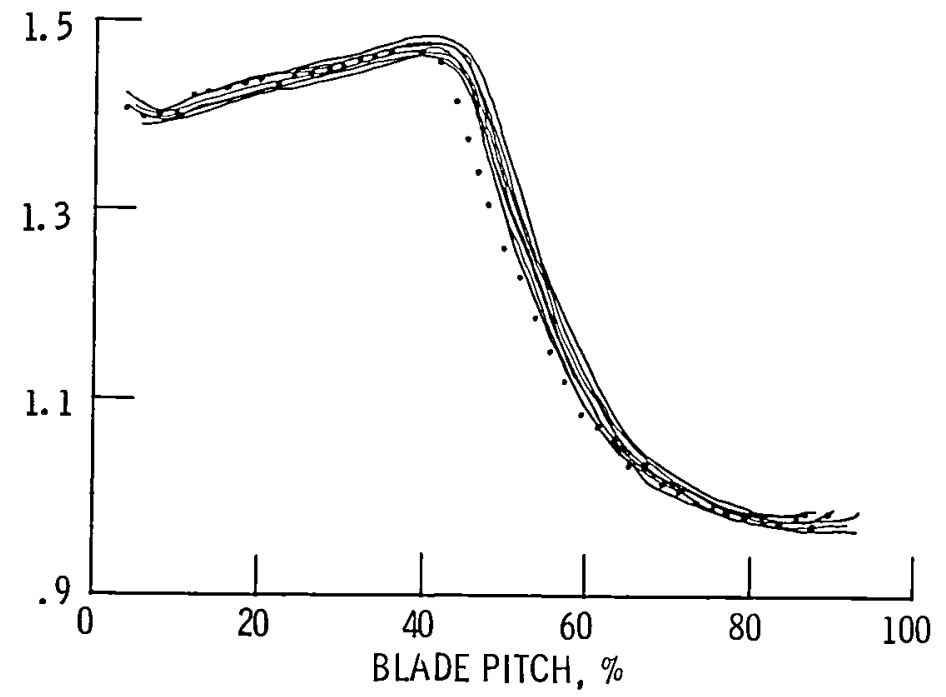

(b) $30 \%$ span, $20 \%$ chord near stall.

Figure 3. - Blade-to-blade distribution of relative Mach number across 17 blade passages. (.... Passage number 12). 


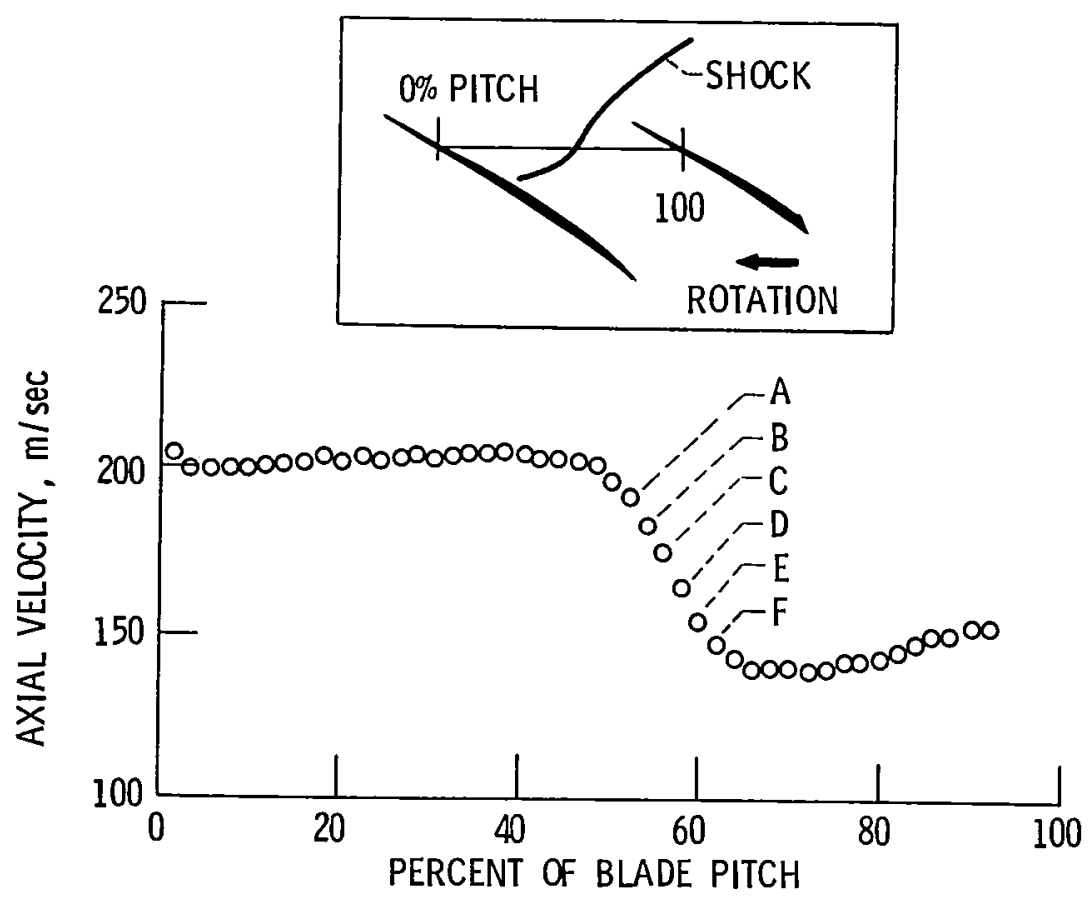

Figure 4. - Blade-to-blade distribution of mean axial velocity component at $10 \%$ span, $20 \%$ chord for the near stall operating condition. 

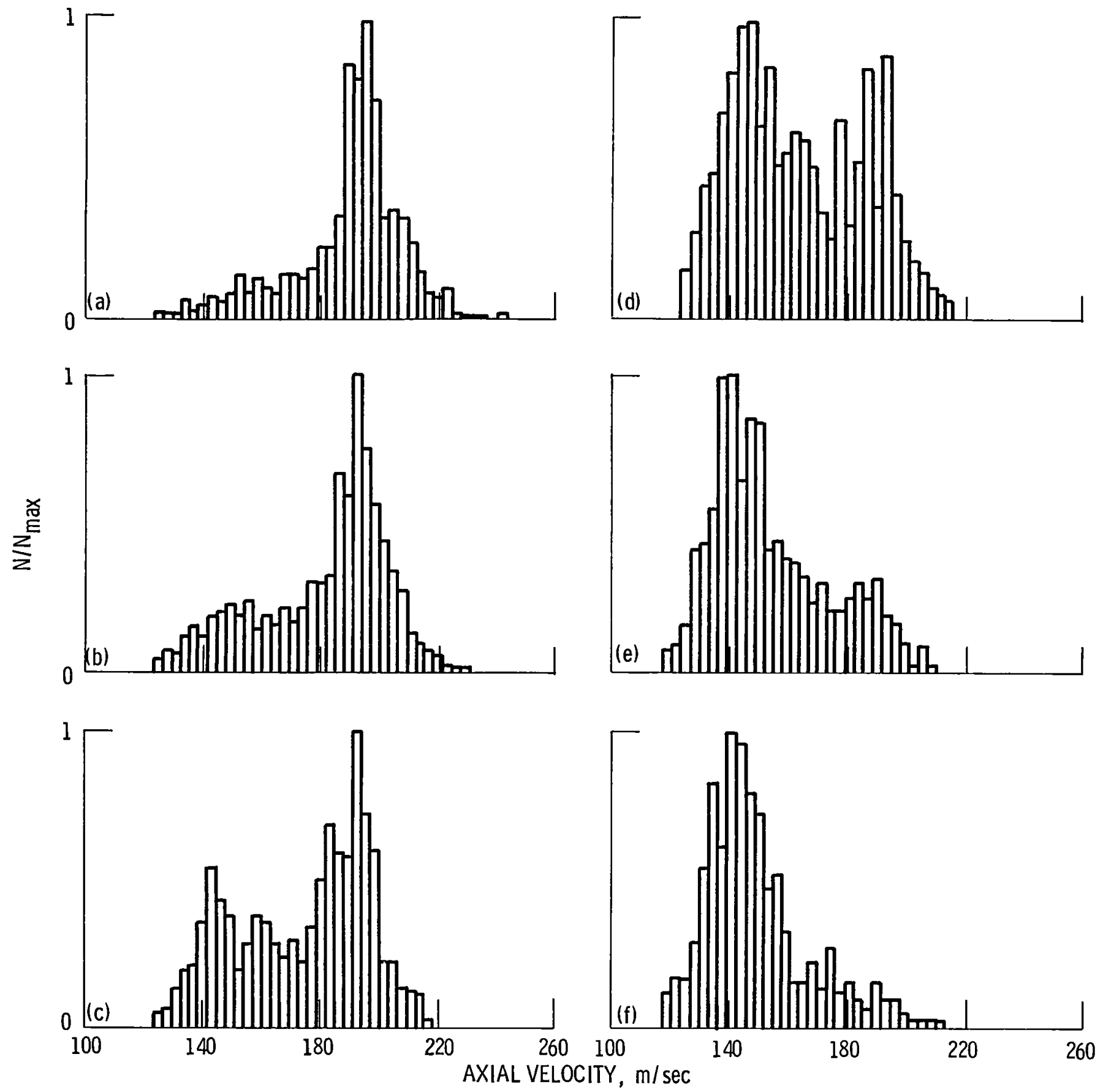

Figure 5. - Normalized distribution of axial velocity measurements at the six points shown in Figure 4 in the vicinity of the rotor passage shock. 


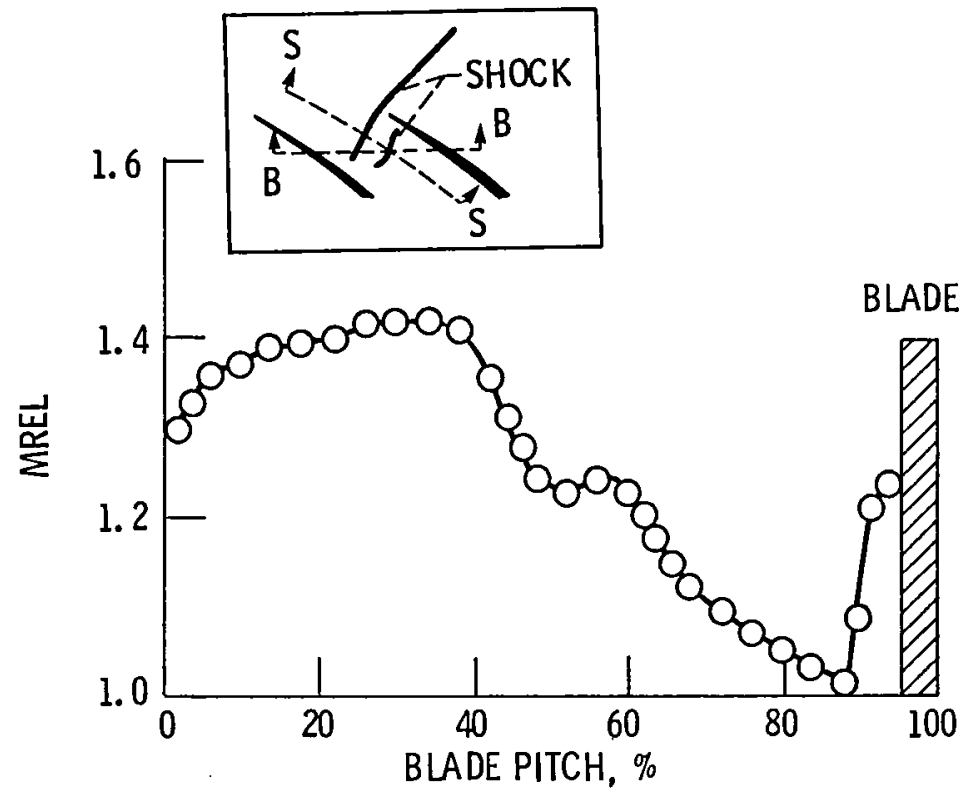

Figure 6. - Blade-to-blade distribution (view B-B of relative Mach number at $30 \%$ span, $30 \%$ chord at peak efficiency.

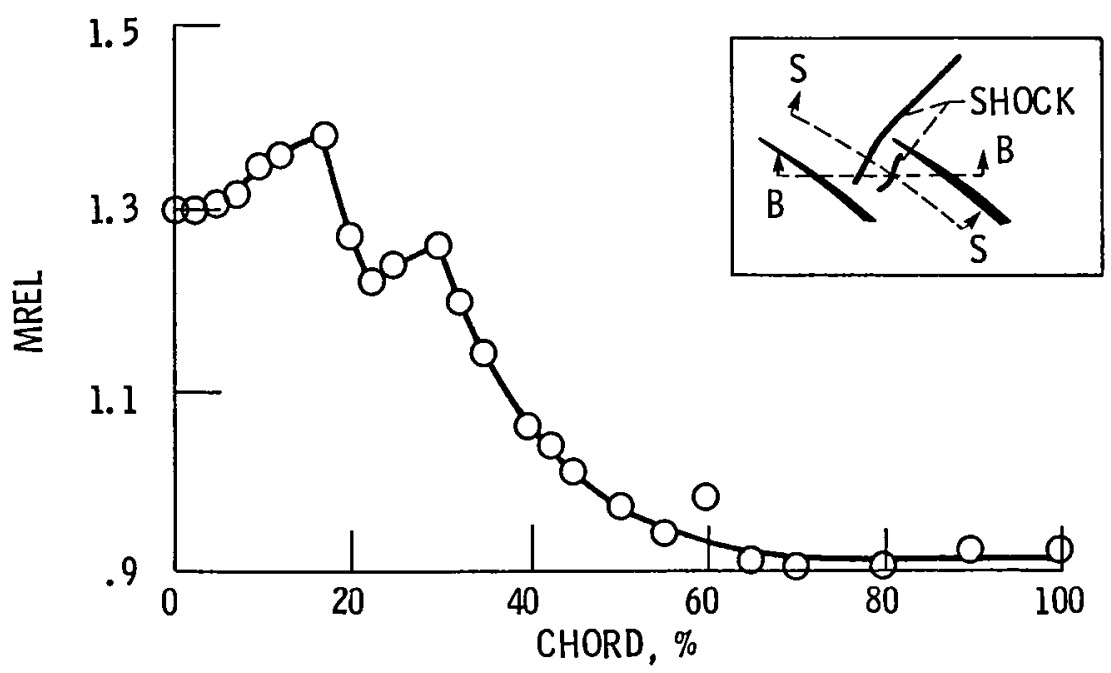

Figure 7. - Streamwise distribution (view S-S) of relative Mach number at $30 \%$ span, $60 \%$ blade pitch from the suction surface at peak efficiency. 
NS - NEAR STALL OPERATING CONDITION

MR - MIDRANGE OPERATING CONDITION

$\beta_{S}$ - SHOCK ANGLE RELATIVE TO THE AXIAL DIRECTION

DF - DESIGN FLOW OPERATING CONDITION

PE - PEAK EFFICIENCY OPERATING CONDITION

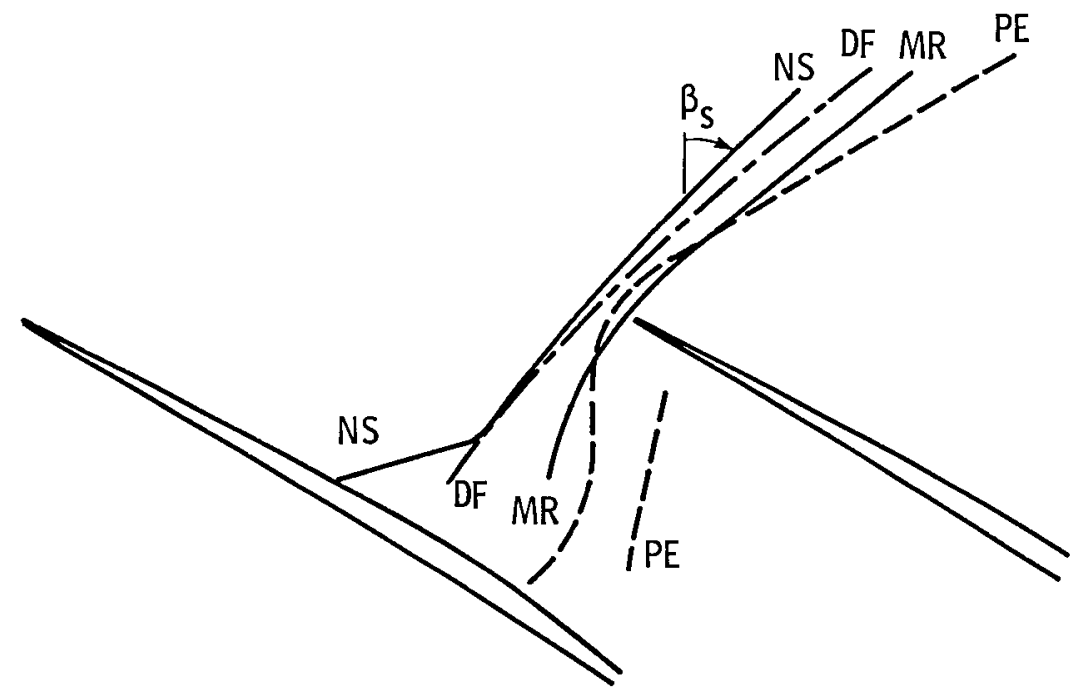

(a) $10 \%$ span.

NS - NEAR STALL OPERATING CONDITION

MR - MIDRANGE OPERATING CONDITION

PE - PEAK EFFICIENCY OPERATING CONDITION

CH - CHOKE FLOW OPERATING CONDITION

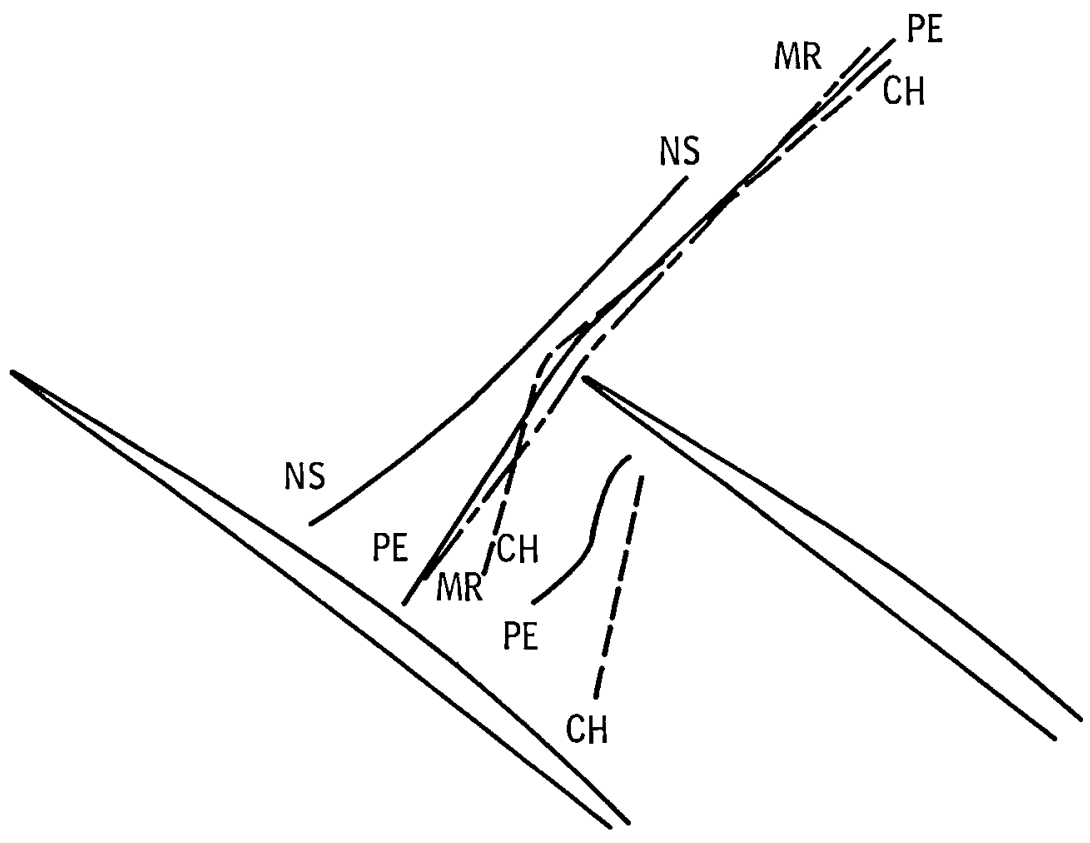

(b) $30 \%$ span.

Figure 8. - Rotor shock structure at design speed for various operating conditions. 

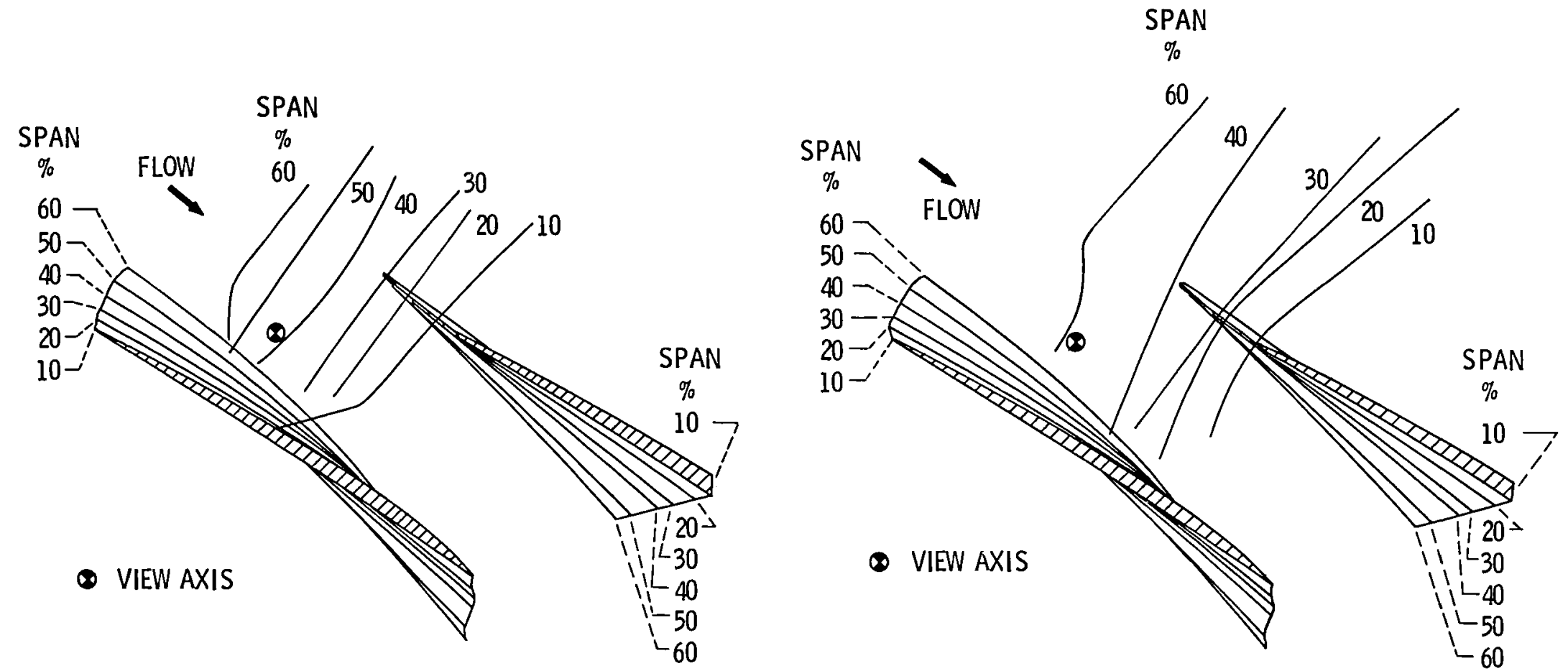

(a) Near stall (NS) operating point.

(b) Midrange (MR) operating point.

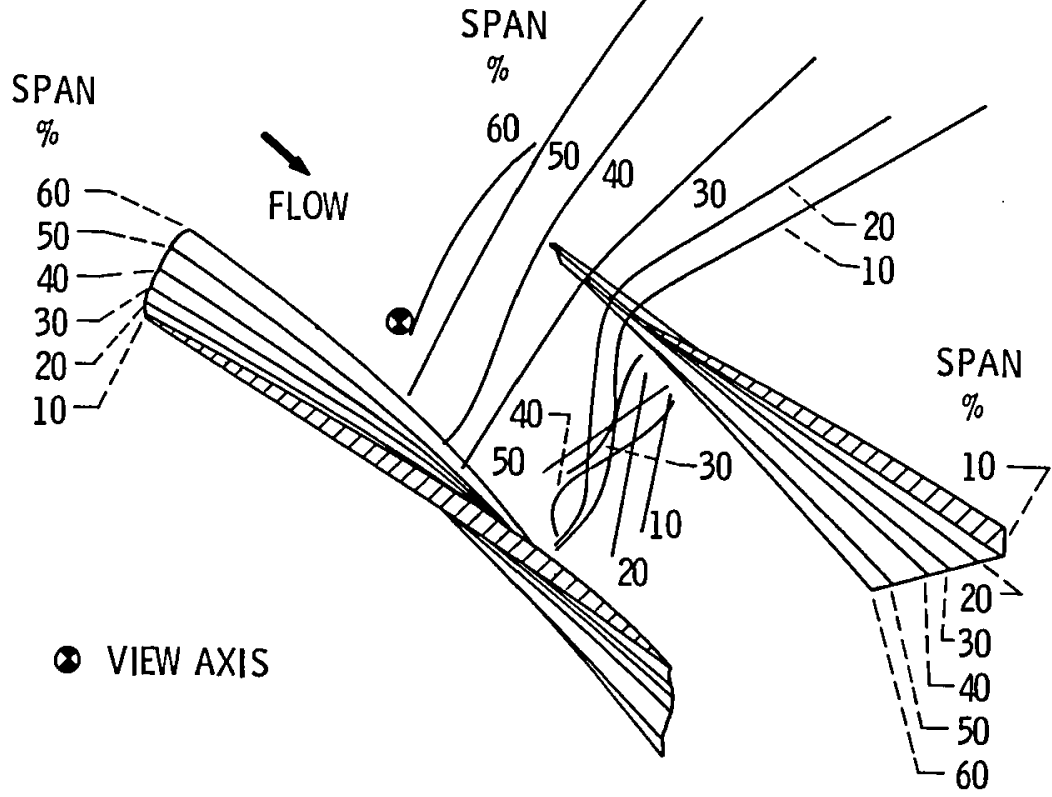

(c) Peak efficiency (PE) operating point.

Figure 9. - Spanwise rotor shock structure. 


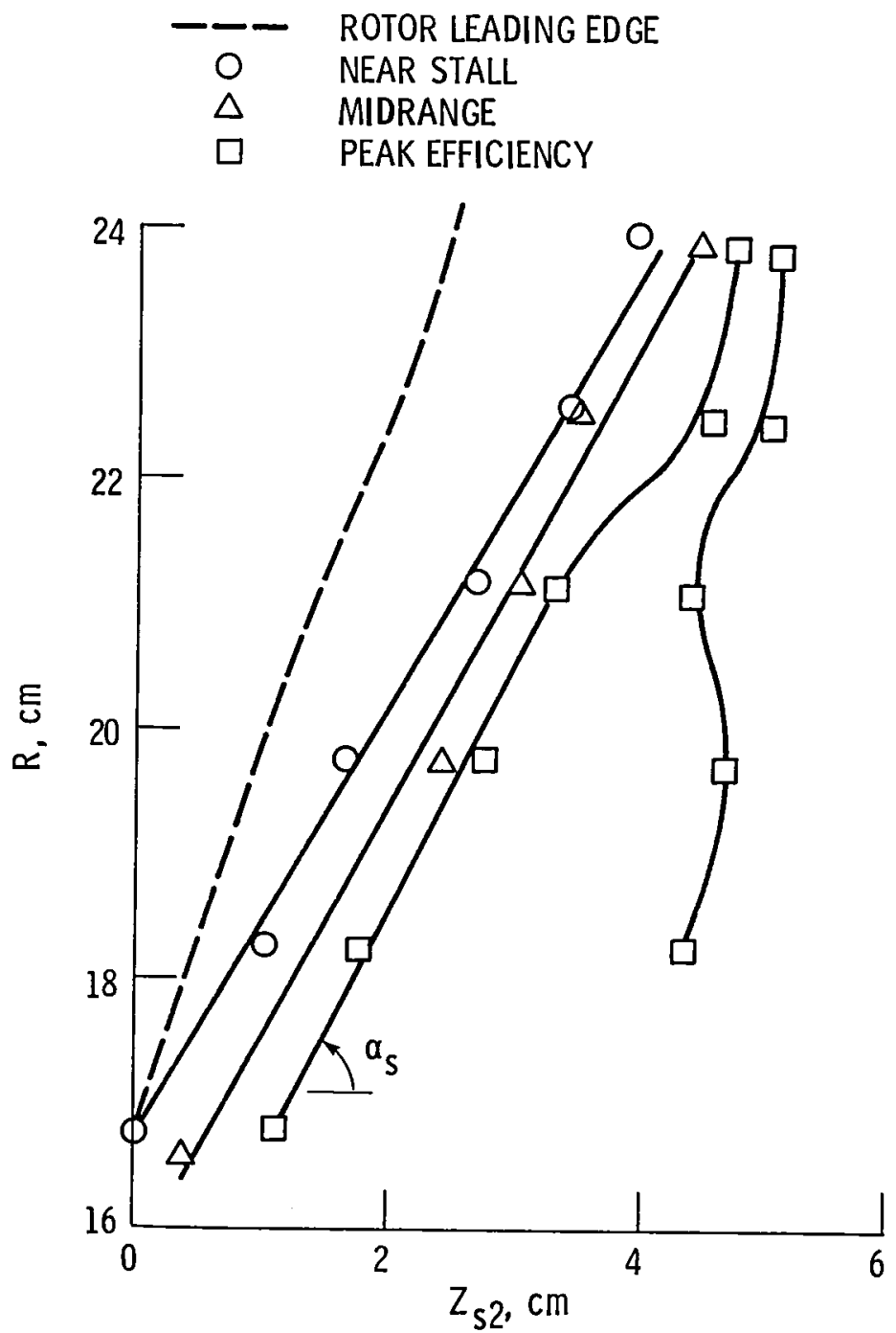

Figure 10. - Intersection of rotor passage shock with the midgap hub-to-shroud streamsurface. 


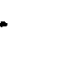




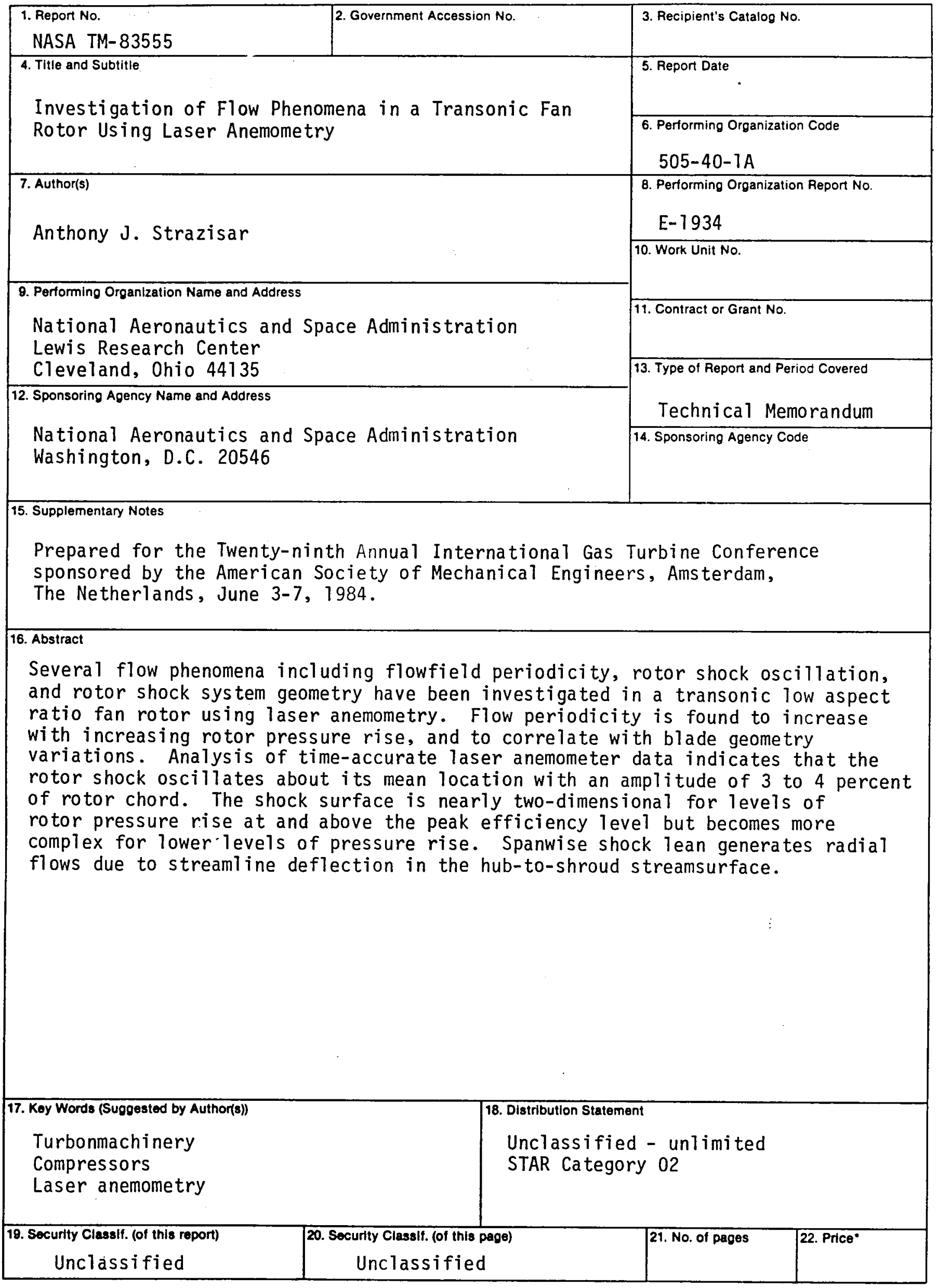

"For sale by the National Technical Information Service, Springfield, Virginia 22161 


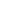


National Aeronautics and Space Administration BOOK

Washington, D.C.

20546

Official Business

Penalty for Private Use, $\mathbf{\$ 3 0 0}$

III

ANGIEY RESEARCH CENTER

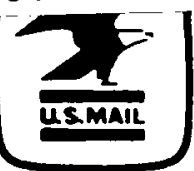

Postage and Fees Paid National Aeronautics and Space Administration

NASA-451 